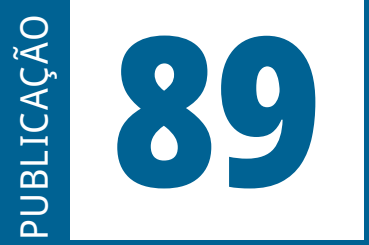

ISSN: 0101-9562

ISSN ELETRÔNICO: 2177-7055

SEQÜÊNCIA

Publicação do

Estudos jurídicos

e políticos

Programa de Pós-Graduação em Direito da UFSC

VOLUME 42 - ANO 2021 
SEQUÊNCIA - ESTUDOS JURÍDICOS E POLÍTICOS é uma publicação temática e de periodicidade quadrimestral, editada pelo Programa de Pós-Graduação Stricto Sensu em Direito da Universidade Federal de Santa Catarina - UFSC.

SEQUÊNCIA - ESTUDOS JURÍDICOS E POLÍTICOS is a thematic publication, printed every four months, edited by the Program in law of the Federal University of Santa Catarina - UFSC.

Versão eletrônica: http://www.periodicos.ufsc.br/index.php/sequencia

A publicação é indexada nas seguintes bases de dados e diretórios/

The Publication is indexed in the following databases and directories:

Base OJS

Base PKP

CCN (Catálogo Coletivo Nacional)

Dialnet

DOAJ (Directory of Open Access Journals)

EBSCOhost

Genamics Journalseek

ICAP (Indexação Compartilhada de Artigos de Periódicos)

Latindex

LivRe!

OJS
PKP
Portal de Periódicos UFSC
Portal do SEER
ProQuest
SciELO
Sherpa/Romeo
Sumarios.org
ULRICH'S
vLex

Ficha catalográfica

Seqüência: Estudos jurídicos e políticos. Universidade Federal de Santa Catarina.

Programa de Pós-Graduação em Direito. n.1 (janeiro 1980)-.

Florianópolis: Fundação José Boiteux. 1980-.

Publicação contínua

Resumo em português e inglês

Versão impressa ISSN 0101-9562

Versão on-line ISSN 2177-7055

1. Ciência jurídica. 2. Teoria política. 3. Filosoia do direito. 4. Periódicos.

I. Universidade Federal de Santa Catarina. Programa de Pós-graduação em

Direito

CDU 34(05)

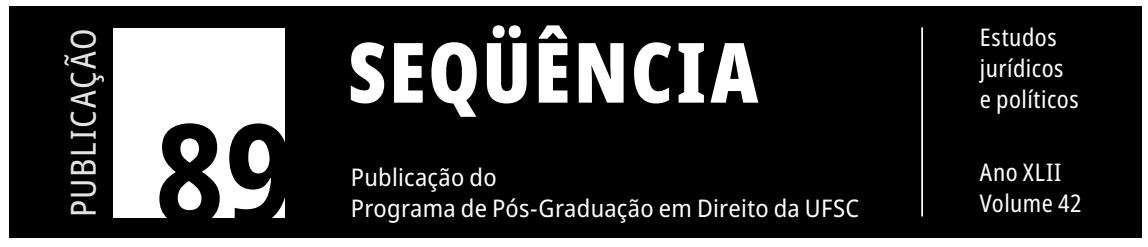




\title{
Da desordem e do caos: o conturbado universo das cadeias locais mineiras na Primeira República (1890-1914)
}

\author{
Disorder and chaos: the troubled universe of local \\ mining chains in the First Republic (1890-1914)
}

\author{
Camila Similhana Oliveira de Souza ${ }^{1}$ \\ ${ }^{1}$ Universidade Federal de Minas Gerais, Belo Horizonte, Brasil.
}

RESUMO: O artigo que se inicia é dedicado a apresentar os resultados obtidos a partir da pesquisa de doutorado financiada pela CAPES defendida em dezembro de 2018 junto ao Programa de Pós-graduação em História da UFMG. Para tanto, foram analisadas as fontes disponíveis no fundo da Chefia de Polícia do Arquivo Público Mineiro, os relatórios da chefia de polícia do estado de Minas Gerais, os relatórios de promotores e as correspondências emitidas pelos delegados de parte das localidades mineiras no período situado entre 1890 (quando entrou em vigor o código penal brasileiro e ganhou força processo de urbanização na região Sudeste) e 1914 (quando a proximidade com a Primeira Guerra Mundial fez com que questões associadas à segurança pública ficassem em segundo plano). O diálogo proposto se mostrou produtivo em virtude de serem as fontes elencadas um rico universo onde são tratados aspectos policiais, criminais e carcerários sob diferentes perspectivas, tornando o estudo do contexto multifacetado. Ao longo do presente artigo optou-se por apresentar parte deste amplo contexto focando as cadeias mineiras situadas junto às delegacias locais de modo a traçar um microcosmo das mazelas que assolavam o ambiente prisional brasileiro no decorrer das primeiras décadas do regime republicano brasileiro.

Palavras-Chave: República - Cadeia local - Minas Gerais.

ABSTRACT: The article that begins is dedicated to presenting the results obtained from the doctoral research funded by CAPES defended in December 2018 with the 
Graduate Program in History at UFMG. The presented thesis was built based on the partial analysis of sources available in the background of the Chief of Police of the Public Archives of Minas Gerais, by confronting the reports of the police chief of the state of Minas Gerais, the reports of prosecutors and correspondence issued by the delegates of mining towns in the period between 1890 (when the Brazilian penal code came into force and the urbanization process gained strength in the Southeast region) and 1914 (when the proximity to the First World War caused issues related to public security to remain in the background). The proposed dialogue proved to be productive due to the fact that they are sources that deal with related themes - that is, the police, criminal and prison universe - from different perspectives, making the analysis of the mentioned context very useful. It is pertinent to remember that when researching the mining chains located next to the local police stations, it became possible to trace a microcosm of the problems that plagued the Brazilian prison environment during the first decades of the First Republic (1889-1930).

KeYWORDS: Republic - Local jail - Minas Gerais.

\section{INTRODUÇÃO}

O artigo em questão foi redigido tendo por base uma preciosa vastidão documental ainda pouco explorada: cerca de vinte e quatro mil fontes, subdivididas em quarenta e três caixas, disponibilizadas ao público somente em 2013 pelo Arquivo Público Mineiro. Até 2014, quando iniciei a pesquisa de doutorado que levou à análise de parte deste escopo documental, não havia estudos a respeito. Tal cenário revelou uma oportunidade ímpar de tratar questões relativas à história das prisões brasileiras, mais precisamente a respeito das cadeias locais mineiras, como também parte do processo sociocultural que abarcava a exclusão, a repressão e o encarceramento das camadas populares.

As fontes mencionadas se destacam por discutir diferentes assuntos sobre o ambiente prisional nas localidades mineiras ao longo dos anos iniciais da Primeira República, quando se deu a publicação do primeiro código penal brasileiro e o início do processo de urbanização citadino na região Sudeste. O progressivo incremento urbano desencadeou, segundo Boris Fausto (2001, p. 26), constante sensação 
de insegurança, sentimento este que tornou o fenômeno criminal um elemento integrante do cotidiano. O assunto, dessa forma, se converteu em uma preocupação cada vez maior tanto por parte das autoridades quanto por parte de segmentos sociais cada vez mais amplos.

As fontes mencionadas se destacam por discutir diferentes assuntos sobre o ambiente prisional nas localidades mineiras ao longo dos anos iniciais da Primeira República, quando se deu a publicação do primeiro código penal brasileiro e o início do processo de urbanização citadino na região Sudeste. O progressivo incremento urbano desencadeou, segundo Boris Fausto (2001, p. 26), constante sensação de insegurança, sentimento este que tornou o fenômeno criminal um elemento integrante do cotidiano. $\mathrm{O}$ assunto, dessa forma, se converteu em uma preocupação cada vez maior tanto por parte das autoridades quanto por parte de segmentos sociais cada vez mais amplos.

Frente às primeiras impressões relatadas, notou-se que os municípios abrangidos pelas fontes eram muitos e o universo documental que abarcavam era muito grande para ser estudado dentro do período disponível para a concretização da tese doutorado, se tornando necessário separar os registros em quadriênios, os quais foram agrupados da seguinte maneira: 1890-1894, 1900-1904, 1910-1914. Isso não impediu que a quantidade de fontes analisadas continuasse alta (cerca de dezesseis mil e duzentos documentos), se mostrando essencial que fossem escolhidas cidades que apresentassem conteúdo de maior relevância diante dos objetivos pretendidos e da delimitação temporal abarcada. Essa delimitação levou a cinco localidades: Sabará (historicamente pertencente à comarca do Rio das Velhas), Diamantina (historicamente situada na comarca de Serro Frio), Guanhães (historicamente situada na comarca de Serro Frio), Barbacena (inicialmente inserida na comarca do Rio das Mortes e posteriormente anexada à comarca de Paraibuna) e Juiz de Fora (inicialmente inserida na comarca do Rio das Mortes, antigo distrito de Barbacena e posteriormente anexada à comarca de Paraibuna).

Após delimitar o período e as cidades que seriam investigadas, o número de registros a serem analisados caiu para seiscentos e dez. 
Desses últimos foram aproveitados quinhentos e setenta, os quais foram separados por eixos temáticos e cronológicos relacionados aos assuntos tanto de maior ocorrência quanto de maior relevância para o universo prisional das cadeias locais. De um modo geral, os documentos escolhidos discutem questões básicas para a manutenção da dignidade dos encarcerados, tais como: condições físicas dos espaços prisionais, alimentação, vestuário, atendimento a presos acometidos por doenças físicas e mentais, bem como a transferência de internos após o julgamento para instituições prisionais adequadas. Os dados coletados versavam acerca de distintos aspectos que pautavam a segurança pública no estado mineiro como os tipos de crimes cometidos, diligências policiais, rol de pronunciados e de condenados, presos doentes, presos mortos, presos transferidos, fugas etc.

É importante ressaltar ainda que o presente artigo foi escrito de forma a associar as fontes pesquisadas, as cadeias locais e os problemas por elas enfrentados dentro de períodos e situações semelhantes. Por conta disso, determinadas cidades e delimitações temporais podem aparecer mais de uma vez, nem sempre de forma linear, ao longo do texto em contextos distintos.

\section{PRINCIPAIS PONDERAÇÕES ACERCA DA ANÁLISE DAS FONTES}

A correspondência entre delegados e chefes de polícia, apesar de seguir determinadas formalidades, não é estanque, assim como os relatórios da chefia de polícia. Prova disso é que não se tratam de fontes rigorosamente homogêneas, aspectos esses que permitem perceber as preocupações, as falhas e as ausências no tocante à temática prisional. André Rosenberg e Luís Francisco de Souza (2009) assinalam que o trabalho com esse tipo de fonte permite compreender que por mais objetivas que sejam, revelam "vetores técnicos - a linguagem jurídica - e axiológicos - os valores apregoados a cada dimensão dos discursos presentes" (p. 168). Deve ressaltar-se, assim, que apesar de serem 
construções advindas de profissionais que servem ao poder público, revelam crenças, valores e representações sociais mais amplas do corpo social em que estão inseridos, ainda que de forma velada, aspecto esse que deve ser considerado e confrontado com as informações emitidas pelo documento.

A perspectiva de Rosenberg e Souza (2009, p. 168) corrobora o quadro traçado por Teresa Malatian (2009, p. 199) quando essa explica que a partir do século XIX desenvolveu-se uma indústria em torno da produção de cartas que permite ao historiador a possibilidade de decodificar as nuances socioculturais de um determinado período, já que são capazes de expressar "dimensões culturais do sujeito, (...) já que esse participa de diferentes 'esquemas de ação e de pensamentos que possuem seus modos de tradução simbólica e constituem sistemas referenciais valorizados'." (Malatian, 2009, p. 200)

Assim sendo, o uso da carta como fonte é reveladora no sentido de conectar as vivências de um indivíduo dentro do universo em que está inserido, funcionando como "junção de experiências referidas a tempos e contextos heterogêneos" (Malatian, 2009, p. 200), que efetivam a relação com os viventes de um dado contexto referente a um período específico. Ainda assim, na prática, nem sempre o conteúdo desses documentos é exposto de forma ordenada ou hierarquizada, mesmo em se tratando de versões que atendem a órgãos de poder o que presume um cuidado ainda maior com a crítica documental, em razão das "informações nelas contidas serem sempre versões individuais ou coletivamente construídas sobre determinados acontecimentos vividos pelo narrador ou dos quais se inteirou de diversas formas como conversas, leituras e relatos." (Malatian, 2009, p. 204)

A perspectiva explorada por Malatian (2009) pode ser percebida junto às correspondências expedidas pelos delegados em meio à pesquisa relatada, quando o argumento daqueles para terem atendidas as solicitações em relação aos presos provisórios passam longe da objetividade burocrática e ganham contornos de clamores religiosos que as aproximam de pedidos desesperados, talvez por que não fosse 
suficiente a solicitação de natureza profissional para que os recursos solicitados ao chefe de polícia fossem atendidos.

A partir das características enunciadas, a carta deixa de ser apenas fonte de informação para se converter em fonte de investigação, já que estabelece a possibilidade de que possam ser empreendidas redes de sociabilidade entre remetente e destinatário, indivíduos e grupos. (Malatian, 2009, p. 203) No caso das correspondências expedidas pelos delegados de polícia, observa-se uma tentativa de conectar as comunicações remetidas por delegados à assistência do chefe de polícia para sanar os problemas enfrentados pelas cadeias locais. O chefe de polícia, por sua vez, procurava articular todo esse material de modo a convertê-lo em um anuário estatístico sobre o enfrentamento da criminalidade e dos problemas relativos à questão prisional em Minas Gerais de modo um tanto quanto tendencioso, pois era comum que usasse os aparentes resultados da atuação no cargo para conquistar outras posições de prestígio na política.

Walnice Galvão e Nádia Gotlib (2000) conceituam as cartas como "versões ficcionadas daquilo que nos querem dizer, existindo um hiato profundo entre o que o autor da carta nos quis comunicar, o que ele escreveu na carta e aquilo que o destinatário mais tarde lerá.” (GAlvão e Gotlib, 2000, p. 15) Isso significa que, para as autoras citadas, as cartas trazem um jogo de estados textuais que modelam a leitura da realidade que apresentam, aspecto esse que deve ser considerado por aqueles que as analisam. Por conta das características descritas, as autoras destacam a dificuldade de estabelecer um parâmetro metodológico para que as cartas sejam empregadas como documento junto às pesquisas em razão de ser esse tipo de fonte de caráter demasiadamente plural, o que, de outro lado, traz a vantagem de permitir uma maior flexibilidade quando são empregadas como objeto de estudo.

Angela de Castro Gomes (2004, p.14-15), de outro lado, diverge da discussão efetuada por Galvão e Gotilib (2000) à medida que destaca a incorporação de novos objetos à prática historiográfica, o 
que exigiu não apenas a construção de novas metodologias e novas categorias de análise, mas também o enfrentamento da dimensão subjetiva que documentos como as correspondências apresentam, cenário esse sintetizado pela autora como um contexto em que deve

(...) ser descartada a priori qualquer possibilidade de se saber 'o que realmente aconteceu' (a verdade dos fatos), pois não é essa a perspectiva do registro feito. $\mathrm{O}$ que passa a importar para o historiador é exatamente a ótica assumida pelo registro e como seu autor a expressa. O documento não trata de "dizer o que houve", mas de dizer o que o autor viu, sentiu e experimentou, retrospectivamente, em relação a um documento. (...) (Gomes, 2004, p. 15)

Diante da perspectiva apresentada, Gomes (2004, p. 16-17) chama a atenção para a ideia de que o texto não é uma construção do autor visando à materialização de uma identidade que ele deseja consolidar e nem o autor uma invenção do próprio texto: a escrita cria, simultaneamente, a identidade do autor e do texto, o que passa pelo trabalho de ordenação, rearranjo e significação a partir da relação entre autor e narrativa. Esta relação é submetida a mecanismos de contenção e aceitação social tecidos pelos preceitos vigentes em uma determinada sociedade de um período específico. Neste universo, Gomes (2004, p. 18) destaca a relevância do domínio do tempo no ato da escrita, visto que essa particularidade auxilia no processo de ordenação da narrativa, o que se manifesta em detalhes como a numeração de páginas, a datação e a localização do que se escreveu ou mesmo pela ordenação das coletâneas de correspondências em caixas ou pacotes para serem armazenados em arquivos domésticos ou institucionais.

Os registros escritos de natureza profissional, definidos por GOMES (2004, p.18) como uma escrita parcialmente pessoal, mas não íntima, se submetem a uma fórmula com alto nível de especificidade, que inclui um conjunto de regras rigidamente estabelecidas, que passam por um modelo muitas vezes exclusivo de papel, timbre, 
envelope, datação, forma de tratamento, despedidas e assinatura. (Gomes, 2004, p. 20).

Frente às peculiaridades elencadas a respeito do tratamento dispensado à análise das correspondências, MALATIAN (2009) descreve que as cartas devam ser confrontadas com fontes de outra natureza para que se seja possível traçar um espectro com as diferentes nuances do objeto em estudo de forma a reconstruir o contexto e "unir as duas pontas da correspondência" capazes de aproximar receptor e destinatário para que seja possível traçar um quadro analítico com a riqueza que esse tipo documental permite. (Malatian, 2009, p. 204) Conforme afirmação de Teresa Malatian (2009, p. 205):

Ainda que as cartas sejam dotadas de grande potencial expressivo, vale aqui a mesma regra de método usualmente empregada na historiografia: nenhum documento pode iluminar por si só um tema. A confrontação com outros documentos se impõe, abrindo ao historiador novas perspectivas e novos ângulos de compreensão. Tal procedimento também evita a ilusão de que o material obtido nas correspondências constitui verdade bruta e inexplorada, confiável uma vez garantida sua "espontaneidade" e, portanto, sua "veracidade". (Malatian, 2009, p. 205)

Em relação às correspondências emitidas pelos delegados das cidades mineiras confrontados com os relatórios da chefia de polícia, tais fontes nem sempre apresentam informações que concordam entre si, disparidade que revela muitas vezes a ênfase ou o desinteresse da instituição em se colocar diante de determinados comportamentos. (FAusto, 1983, p. 196) Se alargarmos esse raciocínio para pensar a questão prisional em meio à documentação analisada, podemos questionar a disparidade entre a grande produção numérica de correspondências relatando os grandes desafios das prisões provisórias mantidas junto às delegacias e o pouco espaço desses reclames nos relatórios da Chefia de Polícia, onde não são exibidos com a mesma relevância e aparecem de forma secundária - se comparados ao espaço concedido 
para descrever a ação da polícia e o combate aos crimes ocorridos nos municípios mineiros -.

Havia, de um lado, interesse e urgência por parte das delegacias em resolver problemas sérios relativos à segurança dos edifícios, à vigilância dos detidos e às questões básicas para a sobrevivência desses, já que estavam sob a custódia do Estado. Enquanto isso, os chefes de polícia, cargo em que muitos ocupantes depois eram transferidos para funções de maior prestígio, se interessavam em listar os crimes reprimidos e a atuação dos policiais, provavelmente para demonstrar sua capacidade atuação e liderança da força local em troca da permuta por cargos de maior importância, sem se preocupar com a ocupação indevida das detenções provisórias em delegacias, muitas delas desnecessárias sob o ponto de vista legal.

Segundo Boris Fausto (1983, p. 197), as prisões provisórias da Primeira República estavam comumente abarrotadas de "figuras contravencionais, bem como as 'prisões para averiguações', o que revela uma estrita preocupação com a ordem pública, supostamente ameaçada por infratores das normas do trabalho, do bem viver, ou simplesmente pela indefinida figura do 'suspeito' [para averiguação].”. Nas cidades mineiras não era diferente, ou seja, muitos eram os encarcerados, poucos eram processados e julgados, menos ainda eram os transferidos para casas de correção de maior porte. Ali eram frequentemente mantidos por um período muito superior ao que havia sido previsto inicialmente por conta da lentidão processual ou em virtude das limitações enfrentadas para efetivar a transferência rumo às grandes casas de correção, mesmo aquelas que no período eram tidas como maiores e mais estruturadas.

As cadeias das delegacias de caráter provisório dão a entender serem não apenas lugares daqueles que estão à espera de averiguação e/ ou julgamento, mas, sobretudo, um "abrigo" para os que são rejeitados socialmente (a exemplo dos loucos e de outros cuja presença não é tolerada) sem que se saiba exatamente o que fazer com eles, conforme relatado em duas das fontes analisadas: 
Officio ao delegado

Ha meses está acorrentado em infecto xadrês da cadêa desta cidade um pobre louco mantido pela autoridade policial no intuito de defender a população dos seus inconscientes attos. E como integram a segurança possuindo a cadêa só essa cama, que se acha superlotada de criminosos, vê se autoriza na cidade uma absoluta necessidade de tê-lo encomendado sem esperança daquelle" recomenda que o doido preso como delinquente em ferros seja transferido para "um hospital proprio ou mesmo para a cadêa da Capital onde offereça mais commodidade e poderá para tratamento então." Saude e Fraterniade. Ao Illmo Exmo Sr Adalberto Ferraz - D.D. Chefe de Polícia do Estado de Minas. De- Promotor de Justiça da Comarca de S Miguel de Guanhães - Pedro Soares. 16 de Dezembro de 1892.( POL 12, Série 12, Cx 03, PC 04 )

Como pode ser observado, as cadeias das delegacias locais iam muito além da função precípua de abrigar presos provisórios e quando condenados, à espera de transferência, mas funcionavam como uma espécie de "depósito" para os indivíduos que de algum modo perturbavam a ordem e cuja presença não fosse tolerada socialmente, tivessem cometido algum crime ou não. A função que deveria ser exercida por uma casa de saúde ou por um manicômio judiciário muitas vezes era desempenhada pelas cadeias locais, mesmo com toda a espécie de limitações que contavam.

O contexto apresentado dialoga com o que é sustentado por Michelle Perrot (2001, p. 236), que compreende o século XIX como um lugar privilegiado para estudar a história das prisões, já que as autoridades do período, ao ampliar a noção de delitos, normas e interdições, acabaram "fabricando" intensamente delinquentes. Diante desse cenário, “(...) a ampliação da prisão é correlata, visto que o encarceramento funda a organização prisional contemporânea. O Antigo Regime certamente conhecera os cárceres, mas antes despejos, locais de passagem do que de permanência e penitência, (...) o encarceramento não constituía a pedra angular da repressão.” (РеRrot, 2001, 
p. 236). Foi, assim, somente no decorrer dos oitocentos que a pena privativa de liberdade passou a sustentar o sistema penal e estimulou a articulação de uma rede de apoio que passará por casas de justiça, de detenção, de correção, entre outras instituições do gênero. Frente ao exposto, o século XIX disponibiliza uma grande quantidade de fontes a respeito dos encarcerados, mas de outro lado aponta poucos testemunhos dos mesmos, vistos então como indivíduos que se rebelaram frente aos preceitos de controle social, os quais devem ser submetidos, monitorados e reconduzidos, mas sem necessariamente abrir canais para que se expressassem diretamente.

O quadro traçado por Michelle Perrot (2001) é muito semelhante ao cenário detalhado pelas fontes da Chefia de Polícia em Minas Gerais quando delegados, juízes e promotores falam dos prisioneiros e com os prisioneiros, mas dificilmente estes últimos tem voz direta na correspondência analisada. Quando muito, as demandas apontadas pelos internos passam pelo crivo do delegado, que se converte em uma figura central para legitimar as necessidades dos encarcerados.

Ainda assim, o que os delegados deixam entrever acerca da realidade prisional não é apenas a visão do opressor, mas uma das poucas vias pelas quais podemos entrar em conexão com parte dos universos dos detidos, muitas vezes emudecidos pela exclusão social, pela repressão policial e pelas agruras do cerceamento das liberdades.

Perrot (2001, p. 237-238) enumera três fatores para explicar o silêncio dos encarcerados nas narrativas históricas: entre os detidos, o percentual de analfabetos era superior ao da população em geral; a recusa da palavra ao detento pela própria instituição prisional, que mesmo quando concedia àquele a oportunidade de falar, destruía ou limitava o acesso a esse testemunho e, por fim, a vergonha social que cercava o prisioneiro, cerceando a possibilidade dele de se colocar, quase como se não tivesse esse direito. A respeito disso, Perrot (2001, p. 239) enuncia a necessidade de que "esses prisioneiros, desaparecidos de sua história, têm de ser rastreados no que se diz deles." 


\section{INADEQUAÇÃO DE ESPAÇOS, ACOTOVELAMENTO DE DETIDOS E PARCA HIGIENE}

Considerando as especificidades apresentadas pelas fontes analisadas, nota-se que muitos eram os problemas dos edifícios que abrigavam as delegacias locais e, consequentemente, as cadeias. Para começar a traçar as diferentes nuances deste panorama, partiremos da situação encontrada em Juiz de Fora, onde mesmo dois anos depois de ter sido liberada verba para a reconstrução da cadeia da cidade, a segurança do edifício volta a ser assunto, mesmo com os reparos executados em 1911:

Urge que Vossa Excelência tome viáveis medidas não só para a limpeza e hygiene da cadeia local, de cujo estado infecto e insalubre dou aqui uma ideia, como também á segurança do edifício que nos oferece resistemcia eficaz de possíveis tentativas de fuga de seus numerosos ocupantes. Creia Vossa Excelência que a minha impressão é fiel e indissimulável, e que a procrastinação das providencias que arbitro e insistentemente peço pode ocasionar lamentáveis consequências em ponto de vista da assistência e tutela que o Estado deve á vida desancar... e da segurança com que as deve censurar á disposição da Justiça Publica para julgamento dos seus processos e cumprimento das decisões desta. No que toca a este ultimo ponto de vista não é de menor necessidade e argumento do destacamento notoriamente insuficiente para a custodia da cadeia e para as demais exigências do serviço policial. Por fim reviso a Vossa Excelencia o pedido já feito da urgente vinda de um delegado militar que possa, pela sua. (Arquivo Público Mineiro, Fundo da Chefia de Polícia, POL 12, Cx 30, Pc 8, jul/1911)

Em Diamantina, os problemas do edifício que abrigava a delegacia e o cárcere municipal não eram muito diferentes daqueles observados em Juiz de Fora, conforme indicado pelo termo de visita às prisões e audiência aos presos, ocasião em que comumente era realizada inspeção da cadeia pelo promotor de justiça e pelo juiz que atuavam naquela circunscrição com presença do delegado local, de 
nome João Raymundo de Morais. O espaço prisional diamantinense apresentava problemas comuns para estabelecimentos do gênero no período, a exemplo do assoalho, que se encontrava, de acordo com o relatório assinalado, "todo pôdre, sem hygiene alguma e [a cadeia] muito fria, fétida e sem asseio algum". (Arquivo Público Mineiro, Fundo da Chefia de Polícia, POL 12, Cx 20, Pc 01, 1902)

Uma das suposições para explicar esse cenário está na dificuldade do controle da criminalidade crescente, o que levaria a um encarceramento superior à estrutura dos municípios citados, ampliando problemas já existentes nos redutos carcerários, mesmo quando o governo estadual se dispunha a colaborar, tal como observado em Juiz de Fora. Esta perspectiva é confirmada por meio de correspondência escrita ao chefe de polícia em dezembro de 1902, quando o delegado de Diamantina solicita recursos antecipados para o já esperado aumento de presos na cadeia da delegacia:

Actualmente há 16 presos sustentados a expensas do Estado,; entretanto orçei a despeza tendo por base 20 presos, por isso mesmo que espero brevemente, e em virtude de diligencias a que tenho feito proceder, numero que, somado ao actual, talvez exceda, e em muito, o que serviu de baze. Necessitando a cadeia de concertos urgentíssimos, inadiáveis, sob o ponto de vista hygienico da segurança de grande numero de presos que nella se acham, mandei os orçar por profissionais. (Arquivo Público Mineiro, Fundo da Chefia de Polícia, POL 12, Cx 20, Pc 07, dez./1902)

Pode ser percebido que o prédio da delegacia que abrigava a cadeia local já apresentava necessidade de reparos, demandas essas que se agravavam em razão do processo de aumento de detenção, o que demonstrava a necessidade de uma estrutura melhor. Em relatório apresentado após visita de inspeção conduzida em outubro de 1902 pelo promotor de justiça Antonio dos Santos Mourão e pelo juiz José Ferreira da Paixão Filho, emerge uma segunda explicação para o crescimento dos internos junto às cadeias locais: “(...) diversos 
achão-se appellados das sentenças e ate hoje ainda não seguiram ao Tribunal superior (...)." (Arquivo Público Mineiro, Fundo da Chefia de Polícia, POL 12, Cx 20, Pc 01, out./1902) Pode ser depreendido a partir dessa informação que o lento andamento processual dificultava a finalização do processo e com isso a definição do destino do preso, sobretudo em relação ao encaminhamento para instituições prisionais adequadas, caso fosse mesmo condenado. Outra possibilidade estava relacionada a indivíduos que mesmo condenados, eram mantidos nas cadeias locais, sem a devida transferência para institutos prisionais responsáveis por orientar o cumprimento da pena, conforme sintetizado pelo chefe de polícia José Vieira Marques junto ao relatório de 1915:

(...) assumpto que hoje se me apresenta como um dos mais serios problemas administraivos: - o da collocação dos condemnados em condições favoraeis ao cumprimento da pena e á obtenção dos legitimos fins que a sociedade, por seus orgãos legislativos, teve em mira, prescrevendo a reclusão do delinquente por tempo variavel segundo a gravidade do evento damnoso, como meio de desaffrontar-se da lesão de direitos commetida pelo criminoso e de propiciar a este a modificação gradativa dos instinctos reprovaveis, até ao ponto de regeneração por inlfuencia do ambiente da expiação. (Arquivo Público Mineiro, Fundo da Chefia de Polícia, Relatório da Secretaria de Polícia de 1915, p.20)

Cárceres com presos em quantidade superior à capacidade de espaço também eram um problema em Barbacena, que demonstra uma trajetória peculiar no campo prisional: em 1891, conforme informado pelo delegado de polícia da cidade ao respectivo juiz de direito, a cidade sequer dispunha de efetiva cadeia, que naquele período era uma sala onde só era possível "guardar a segurança de tres reus, pois o commando, que serve de prisão, é um quarto formado de tabua fina (...)" (Arquivo Público Mineiro, Fundo da Chefia de Polícia, POL 12, Cx 02, Pc 05, set. 1891). Era um cenário inadequado, portanto, a uma realidade que assistia à elevação tanto de detidos quanto de 
processos instaurados, que iam muito além das possibilidades locais. Em 1897, seis anos depois, a situação prisional da localidade parecia ainda complicada, já que o chefe de polícia mencionou no relatório daquele ano que a cadeia de Barbacena, a qual seis anos antes contava com três presos em uma apertada sala, agora abrigava trinta e três indivíduos em um edifício com problemas a perder de vista.

$\mathrm{Na}$ cidade de Sabará, as condições da cadeia eram tão ruins que a reforma do prédio sequer era requerida, mas pedidos recorrentes de demolição antes que os presos nela mantidos e a respectiva guarda pudessem falecer frente a um possível desabamento, conforme articulado pelo delegado da cidade em correspondência enviada ao chefe de polícia:

Ilustre Cidadão!

A Delegacia de Policia d'esta Cidade de Sabará, sendo sciente que a Intendencia Municipal representou ao Ilustre Governador pedindo a demolição da Cadêa que em ruinas promete perigar a vida dos Presos e a guarda que os vigia, pede-nos o comuniqu recolhimento dos mesmos Prezos para essa Capital, visto ser tão urgente o que os Ilustres representantes do Município reclamão. (...) Sabará, 7 de Março de 1890. Anton (Arquivo Público Mineiro, Fundo da Chefia de Polícia, POL 12, cx 01, pc 03)

Se não havia estrutura para manter os presos sob condições básicas, não era de se surpreender que também fossem comuns as fugas, embora essas ocorrências sejam pouco mencionadas nas correspondências. Em Sabará, o delegado Nicolau Antonio de Padua descreve uma evasão de presos às vinte e três horas da noite, que acreditava ele ter sido motivada por janelas em péssimo estado de conservação, cujas grades externas encontravam-se podres, não podendo evitar, assim, que os presos evadissem (Arquivo Público Mineiro, POL 12, Cx 22, Pc 09, janeiro/1904). João Cezar de Oliveira, delegado de Diamantina, reporta frequente dificuldade para manter o isolamento dos indivíduos detidos: 
(...) a segurança publica, porque, regorgitando sempre de criminosos importantes, pela natureza dos delictos praticados e condições ultrainferiores de educação, temo que, pela fraqueza que em diversos pontos offerecerão suas prisões, dela consigam evadir-se, como por vezes já o tem feito, alarmando sobremodo a população desta cidade. (Arquivo Público Mineiro, Fundo da Chefia de Polícia, POL 12, Cx 20, Pc 12, jan./1902)

Existiam ainda situações em que não havia propriamente fuga, mas a circulação inapropriada de presos, como relatado pelo chefe de polícia Edgardo Carlos da Cunha Pereira no relatório de 1902 quando esse menciona, sem especificar as cidades, que

em diversos municipios continua a dar se o abuso de conceder sahida aos presos, alguns dos quaes permanecem durante o dia fóra das prisões, com grave infracção do art. 23 do Dec. 731, de 3 de agosto de 1894, que deu regimento ás cadeias do Estado, chamo a vossa atenção para o que dispõe o citado artigo, que precisa ser literalmente cumprido. (Arquivo Público Mineiro, Fundo da Chefia de Polícia, Relatório da Secretaria de Polícia de 1902, p. 21)

Um contratempo recorrente enfrentado pelas cadeias das localidades mineiras residia nos meios pouco adequados para que os presos que pudessem realizar necessidades fisiológicas. Nesse sentido, emblemático era o caso de Diamantina, onde se achava "completamente estragada a latrina, bem como parte do assoalho das mesmas; muito feia a prisão, muito sem hygiene, sentindo-se desde ao entrar-se na porta da enxovia e xadrez grande fétido de matérias fecaes em decomposição." (Arquivo Público Mineiro, Fundo da Chefia de Polícia, POL 12, Cx 20, Pc 07, out./1902)

As fontes de Barbacena indicavam, de igual modo, que ainda no ano de 1914, a prisão da cidade continuava a precisar de consertos urgentes, fossem nos assoalhos ou nas latrinas que não funcionavam de forma regular. (Arquivo Público Mineiro, Fundo da Chefia de Polícia, POL 12, Cx 33, Pc 01, set./1914). Frente aos constantes, porém 
inúteis, consertos, o chefe de polícia Américo Ferreira Lopes enfatiza no relatório de 1911 que as cadeias das cidades mineiras

(...) frequentemente carecem de concertos que nunca são bem feitos, avultando os gastos improficuamente. (...) Parece mais acertada a demolição de muitas ellas, construindo-se novas de accordo com os typos existentes na mesma Secretaria, ao envez de repetir-se em pura perda, annualmente, a mesma despesa com os mesmos reparos." (Arquivo Público Mineiro, Fundo da Chefia de Polícia, Relatório da Secretaria de Polícia de 1911, p. 20)

Existem ainda problemas recorrentes com a disponibilidade de água nos estabelecimentos, conforme disponibilizado no relatório enviado ao chefe de polícia após visita de inspeção à cadeia local efetuada pelo delegado João Raymundo de Moraes, pelo promotor de justiça Antonio dos Santos Mourão e pelo juiz José Ferreira da Paixão Filho. No ano seguinte, um novo delegado, Laurindo Augusto Pereira da Silva, encaminhou correspondência ao chefe de polícia reclamando que "na enxovia [de Diamantina] não corre água o encanamento está completamente estragado sendo obrigado a consentir que dois presos buscar agua para a dita prisão e ademais que tambem não corre agua, peço vos auctorisação para este conserto." (Arquivo Público Mineiro, Fundo da Chefia de Polícia, POL 12, Cx 21, Pc 06, dez./1903)

O que pode ser notado nesse tipo de circunstância é que não importa a quem apelasse ou quantas vezes se apelava à chefatura de polícia nem quão grave fosse o problema para enfrentado pelos detidos no estabelecimento prisional, a solicitação era constantemente postergada, sem que fossem tomadas as providências esperadas. Uma das soluções então pensadas era demolir as cadeias para construir novos edifícios em lugar de gastos frequentes, sugestão muito repetida pelos delegados nas correspondências.

A possibilidade era cogitada à medida que os possíveis reparos nos imóveis onde funcionavam as cadeias locais era vistos como uma opção difícil de ser colocada em prática, já que boa parte delas se 
encontrava em "vetustos casarões construidos quando não se cogitava, como agora, da hygiene das habitações, como uma das primordiaes condições de salubridade das povoações." Por conta disso, "as obras de conservação e adaptação com que se procura tornal-as menos improprias ao fim a que se destinam, além de serem de ordinário dispendiosas, não conseguem remediar o incoveniente da reclusão em comum", o que desencadeava, segundo a perspectiva de Américo Ferreira Lopes, "entraves á manutenção da disciplina, sem a qual as prisões se desordenam inevitavelmente." (Arquivo Público Mineiro, Fundo da Chefia de Polícia, Relatório da Secretaria de Polícia de 1914, p. XVIII-XIX) O argumento do governo estadual frente à hipótese de demolir e reconstruir as cadeias locais, todavia, era de que no período não havia verba disponível para a reconstrução de tantos imóveis, daí preferir consertá-las de forma lenta e espaçada, dando tempo, segundo deixam entrever as fontes analisadas, para a recomposição das finanças do governo de Minas Gerais, o que parece ocorrer com grande dificuldade em meio ao período analisado.

Aos delegados que escreviam, diante da ineficiência em resolver as pendências listadas, restava a constatação por parte da chefatura de polícia, a exemplo daquela sustentada por Américo Ferreira Lopes, de que "á excepção de algumas [cadeias], que infelizmente não attingem a um quarto do total, onde se mantém um relativo grau de disciplina e hygiene (...)" (Arquivo Público Mineiro, Fundo da Chefia de Polícia, Relatório da Secretaria de Polícia de 1914, p. XVIII-XIX), as demais cadeias situadas nas localidades mineiras são definidas por como lugares onde "um grande numero de reclusos (...) estão entregues a uma promiscuidade perigosa physica e moralmente, exercitando-se na pratica de vicios abominaveis, enervados pela prolongada apathia e indolencia, desassistidos de toda suggestão capaz de lhes formar as inclinações para o mal." (Arquivo Público Mineiro, Fundo da Chefia de Polícia, Relatório da Secretaria de Polícia de 1915, p. 21). Américo Ferreira Lopes destaca ainda que "tendo visitado, no desempenho de meu cargo, diversas cadeias do Estado, em todas ellas 
notei a falta absoluta de hygiene, sendo o dessasseio o estado normal de quasi todas" contexto esse que o chefe de polícia afirmar se dar "com acquiescencia dos carcereiros e sciencia das auctoridades locaes", a exemplo das recorrentes "denegridas e nauseabundas as paredes e tectos dos cárceres"e outras práticas reprováveis

Frente à contínua precariedade dos encanamentos de esgoto e a insalubridade das cadeias, a saúde dos internos se tornou um tema recorrente das correspondências dos delegados de 1904 em diante. O delegado Nicolau Antonio de Padua de Sabará, por exemplo, requereu o envio de água para limpeza do ambiente prisional e a "compra de barris de madeira para servir de latrina (...), visto ser este serviço feito com latas de querosene." (Arquivo Público Mineiro, POL 12, Cx 22, Pc 09, janeiro/1904), o que tornava a higiene do ambiente prisional sofrível, favorecendo a propagação de diferentes doenças. Em Juiz de Fora, o cárcere da delegacia da cidade defrontava-se com semelhante problema, que por sua vez foi narrado em relatório por um promotor de justiça que inspecionou o local:

O desprezo das matérias fecaes é feito pelo processo mais imperfeito e rudimentar, dentro da própria prisão e enche esta de um ambiente mephytico e nauseabundo, cujos perigos para a saúde dos encarcerados não preciso de assignallar ao espirito culto de Vossa Excelência. Acresse que há falta de agua abundante para ocorrer as necessidades de limpeza das prisões. (Arquivo Público Mineiro, Fundo da Chefia de Polícia, POL 12, Cx 30, Pc 8, jul/1911)

A adversidade apresentada se somava ao exíguo espaço ocupado por uma quantidade de detidos inversamente proporcional ao espaço disponível, resultando no seguinte cenário:

As três prisões de que ella se compõe são compartimentos infectos, insalubres, onde, sem a mais tênue medida de hygiene, se acotovellam 43 detentos. Em uma delas sucumbiu resentemnte um tuberculoso, e ali se consumam, sem o expurgo e as medidas de prophylaxia, alguns dos referidos detentos. 
(Arquivo Público Mineiro, Fundo da Chefia de Polícia, POL 12, Cx 30, Pc 8, jul/1911)

Em Guanhães, o relato do delegado acerca da cadeia local é ainda mais detalhado, contundente e capaz de sintetizar tudo aquilo que foi descrito ao longo das últimas páginas a respeito das prisões locais mineiras. A cadeia da cidade, que em 1901 apresentava necessidade de consertos e integrava uma espécie de lista de espera de espaços prisionais mineiros que aguardavam a confirmação do governo para iniciar reformas já orçadas ${ }^{1}$, é descrita em 1913 pelo delegado da localidade como "em completo estado de ruinas, ocupa a área de 93 metros quadrados; tem dous pavimentos, o inferior com cinco compartimentos; duas prisões na frente, com cubagem de 55,70 metros cúbicos e uma só janela cada uma - um corredor, dous xadrezes e o corpo de guarda ao fundo. O pavimento superior tem trex prisões mais vastas e arejadas, servindo uma dellas, ao fundo, de enfermaria, onde como agora há trez presos atacado de varicela" (Arquivo Público Mineiro, Fundo da Chefia de Polícia, POL 12, Cx 32, Pc 03, 1913). Além das limitações espaciais, a distribuição de janelas parecia insuficiente para que a circulação do ar fosse satisfatória, colaborando para que possíveis doenças pudessem se alastrar com facilidade, a exemplo de um suposto início do surto de varicela, doença infecciosa, transmitida por vírus e altamente contagiosa.

O delegado de Guanhães coloca ainda que "Nas duas prisões inferiores da frente do edifício, há dous buracos fronteiros as janelas que servem de latrinas, servidos por dous anneis d'água no máximo, pelo que continuamente desprendem exhalações mephilitcas, como é facil de prever. É esta a cadeia da cidade de Guanhães!” (Arquivo Público Mineiro, Fundo da Chefia de Polícia, POL 12, Cx 32, Pc 03, 1913) Nesse ponto, perpetua-se um aspecto crônico e muito abordado

1 Arquivo Público Mineiro, Fundo da Chefia de Polícia, Relatório da Secretaria de Polícia, 1901, p. 17. 
nas correspondências das cidades aqui trabalhadas: a dificuldade em manter a salubridade do espaço prisional, tendo em vista a precariedade de latrinas para a satisfação das necessidades fisiológicas dos presos e quando existiam encanamentos, os constantes imbróglios gerados por esses, impedindo assim que satisfizessem sua função primeira de coletar e transportar os excrementos de forma a manter a higiene do local.

Um detalhe presente na correspondência do delegado de Guanhães traz à tona um aspecto repetido sucessivamente nas cartas das autoridades, mas que nenhuma das fontes analisadas ainda havia explicado: a separação entre presos pobres e presos de melhor condição socioeconômico. Ao usar constantemente o termo "presos pobres" para solicitar alimentação, vestuário e cobertores, presumia-se que houvesse encarcerados de condição diferenciada, mas esses últimos nunca são objeto de atenção das fontes analisadas. Era possível imaginar que existissem, senão não haveria a denominação "presos pobres", mas entre as cidades estudadas não havia quem se debruçasse sobre eles, talvez por que fossem poucos ou mesmo por que conseguissem se livrar com mais rapidez da condição de encarcerados. A respeito desse ponto, o delegado de Guanhães é um dos poucos a esclarecer:

Do que fica exposto se verifica claramente de que não há sala livre, visto como, as prisões superiores, são sempre recolhidos ou transferidos os presos de melhor posição social e de melhor comportamento, o que aliás é praxe ou uso admitido em todas as prisões de paizes civilizados, e que sempre tem sido observado por todos os meus antecessores, sem excepção de um só. Actualmente, existem recolhidos às prisões 17 presos, 12 nas inferiores e 5 nas superiores. (...) (Arquivo Público Mineiro, Fundo da Chefia de Polícia, POL 12, Cx 32, Pc 03, 1913)

Com base no exposto, é possível compreender que presos pobres fossem não só aqueles de melhor situação socioeconômica, mas também aqueles que tinham sido detidos por questões políticas e não em decorrência de crimes cometidos, daí supostamente tivessem 
tratamento diferenciado, podendo bancar sua própria alimentação, vestuário e cobertores. Poucas são as sugestões articuladas pelos chefes de polícia para a melhoria do quadro expostos, grande parte deles se dedica a apresentar as vicissitudes do contexto prisional ou tentar demonstrar que o cenário, apesar de continuar com problemas expostos pelos chefes anteriores, não teve suas mazelas aprofundadas. Américo Ferreira Lopes se destaca entre os demais ao dedicar muitas linhas do relatório anual da chefia de polícia para pensar uma possível solução frente aos problemas enfrentados pelas cadeias locais mineiras:

(...) seria medida salutar, pelo menos attendendo-se á vastidão de nosso territorio e ás difficuldades de communicação, mormente no norte e extremo oeste, a construcção de cadeias regionaes, com capacidade para o minimo de 100 presos, dotadas dos requisitos indispensaveis de segurança e hygiene e tendo duas ou tres officinas e uma escola onde os reclusos aprendessem e se exercitassem num officio, e deixassem de ser analphabetos. (Arquivo Público Mineiro, Fundo da Chefia de Polícia, Relatório da Secretaria de Polícia de 1914, p. XIX)

A sugestão do chefe de polícia Américo Ferreira Lopes faz menção a uma instituição prisional intermediária entre as muitas limitações das cadeias locais e as poucas vagas dos espaços para os quais se esperava que fossem transferidos os detidos depois de julgados e condenados. Tratava-se de um empreendimento que na visão de Ferreira Lopes não seria tão dispendioso quanto uma penitenciária, mas com recursos muito maiores e em condições muito mais favoráveis do que uma cadeia local. Sob a perspectiva de Ferreira Lopes, a possibilidade de serem construídas cadeias regionais (em lugar apenas da presença de penitenciárias e cadeias locais) também auxiliaria a desafogar os problemas das cadeias locais das cidades do interior. Segundo o mesmo chefe de polícia, muito ajudaria se "o Estado edificasse o quanto antes cinco dessas cadeias e immediatamente collocasse 500 presos" até que fosse plenamente possível concretizar "o plano da construcção projectada de uma penitenciaria na Capital, pois, havendo nas nossas cadeias cerca 
de 1000 presos condemnados, só a penitenciaria não seria sufficiente para os recolher em sua totalidade" (Arquivo Público Mineiro, Fundo da Chefia de Polícia, Relatório da Secretaria de Polícia de 1914, p. XIX), já que a penitenciária de Uberaba, já disponível em 1915, parecia não preencher as necessidades prisionais do estado no período.

\section{CONCLUSÃo}

O presente artigo procurou compartilhar parte do que as fontes analisadas junto ao fundo da chefia de polícia do Arquivo Público Mineiro abordam a respeito das cadeias locais do estado de Minas Gerais entre 1890 e 1914. Trata-se de uma amostra do universo pesquisado direcionado à análise das condições físicas dos espaços prisionais, já que constituem aspectos de reclamação frequente nas correspondências emitidas pelos delegados aos chefes de polícia. Para a escrita da tese foram considerados os casos mais alarmantes e para a redação do presente texto foram escolhidas as situações mais emblemáticas. Em comum, as fontes analisadas apresentam o testemunho preocupado, de delegados, promotores e juízes estupefatos com as condições enfrentadas pelos detidos nas diferentes localidades mineiras, os quais foram confrontados com os relatórios anuais da chefia de polícia, que não dão o devido destaque ao tema, reduzindo ao máximo a abordagem do mesmo.

Diante da tentativa de explicar a falta de habilidade do governo estadual para resolver os problemas enfrentados pelas cadeias locais, diferentes respostas foram buscadas pelos chefes de polícias nos relatórios anuais. O chefe de polícia Edgardo Carlos da Cunha Pereira, no relatório da Secretaria de Polícia de 1902, associava as dificuldades de em gerir os obstáculos aferidos à forma como o estado mineiro dividia as circunscrições policiais. De modo a resolver esta pendência, Edgardo Pereira sugeria que o estado fosse dividido em “(...) cinco ou seis circumscripções policiaes, tendo cada uma dellas um preposto 
do Chefe de Poícia, em formado em direito, prompto a atender aos reclamos da ordem publica em todo o território sob sua jurisdição. (...)"(Arquivo Público Mineiro, Fundo da Chefia de Polícia, Relatório da Secretaria de Polícia, 1902, p. 7)

O mesmo chefe de polícia sugere que para solucionar o impasse entre os obstáculos enfrentados pelas cidades na seara criminal e penitenciária e a dificuldade da chefatura de polícia em resolvê-los fosse restabelecido "o cargo de Secretario ou Delegado Auxiliar que, substituindo o Chefe de Polícia mas suas faltas e impedimentos, auxilie a este no estudo dos papeis que entram e sahem diariamente do gabinete em elevado numero. (...)"(Arquivo Público Mineiro, Fundo da Chefia de Polícia, Relatório da Secretaria de Polícia, 1902, p. 7). Para Edgardo Carlos da Cunha Pereira, essa mudança seria essencial para melhorar a eficiência dos serviços prestados, ponto este reiterado pelo chefe de polícia Christiano Pereira (Arquivo Público Mineiro, Fundo da Chefia de Polícia, Relatório da Secretaria de 1905, p. 7)

Outra linha de explicação para o comportamento pouco comprometido do governo estadual, mesmo com as questões prisionais mais urgentes, está na suposta crise financeira pela qual passava Minas Gerais entre a década final do século XIX e as primeiras décadas do século XX, quando muitas cidades mineiras foram afetadas por um processo de estagnação econômica decorrente da crise da extração aurífera, levando à redução das lavras de ouro que chegou inclusive a gerar pontos de esvaziamento demográfico. Neste sentido, Edgardo da Cunha Pereira, chefe de polícia que assina o relatório de 1901, coloca em pauta as dificuldades financeiras do estado, que segundo ele estaria "assoberbado igualmente por uma angustiosa crise econômica a que se fiam muitos crimes." (Arquivo Público Mineiro, Fundo da Chefia de Polícia, Relatório da Secretaria de Polícia, 1901, p. 3):

O alto valor a que attingiram os produtos do labor agricola, o extraordinario desenvolvimento que se operou na indústria extractiva, a construção da Capital, a expansão do commercio, no incio do regimen republicano, atrairam para o território 
mineiro em demanda da nossa riqueza incipiente nacionais e extrangeiros, morigerardos, sóbrio e trabalhadores uns, aventureiros outros, avessos ao trabalho e dados á vida facil das especulações, que se viram de momento na sua maioria sem occupação, quando estalou a crise que desvalorizou o nosso principal produto de exportação, desorganizando a lavoura de café, determinou a redução do salário nos serviços de mineração, que não se interromperam, ocasionou a liquidação de diversas empresas de transporte, dando logar á grève dos operários, abalou geralmente o commercio em consequência do numerado, creando a situação dolorosa que a todos nós aflige. (Arquivo Público Mineiro, Fundo da Chefia de Polícia, Relatório da Secretaria de Polícia, 1901, p. 3)

É possível depreender que estivesse o estado mineiro sendo afetado por uma crise econômica em curso, que notadamente tornou problemáticas as oportunidades de obtenção de trabalho, estimulando a migração daqueles que não conseguiam alguma colocação para o mundo do crime. A explicação apresentada pelo chefe de polícia encontra eco no fato de que a última década do século XIX foi um período marcado por conflitos entre as elites mineiras, que não conseguem dialogar de modo a pensar uma entidade e um projeto de desenvolvimento regional comum. Na passagem do século XIX para o século XX, as discordâncias entre as elites entram em uma fase de relativa estabilidade, o que possibilita despertar para a conscientização em torno do atraso trilhado pelo estado mineiro frente a outros da região Sudeste, a exemplo de São Paulo e Rio de Janeiro. Para tanto, dão início a uma articulação política dedicada a pensar a concepção e concretização de projetos para o desenvolvimento regional.

No decorrer da década de 1900, a situação econômica do governo estadual continuou ruim, período esse definido pelo chefe de polícia Christiano Pereira Brasil como grave estado das finanças, em meio a uma fase vista como "difficil quadra que atravessamos e que está a exigir a mais rigorosa economia em todos os ramos da publica administração.” (Arquivo Público Mineiro, Fundo da Chefia 
de Polícia, Relatório da Secretaria de 1905, p. 5) Segundo o mesmo chefe de polícia, as finanças do serviço público tinham sido "golpeadas a fundo nos diferentes ramos, (...) cuja receita se achou subitamente desfalcada de boa porção de suas quotas com a supressão do imposto inter-estadual." (Arquivo Público Mineiro, Fundo da Chefia de Polícia, Relatório da Secretaria de 1905, p.6)

É possível concluir, portanto, que para além da aparente letargia da chefatura de polícia, há um encadeamento de fatores, que vão desde conflitos políticos internos, a falta de verbas, passando pela ausência de pessoal, incluindo ainda a incompatibilidade entre a extensão do estado mineiro e a falta de meios de comunicação que facilitasse o diálogo entre as distâncias para atender com eficiência os diferentes problemas que atingiam a população carcerária mineira que chegava então a dois mil indivíduos. (Arquivo Público Mineiro, Fundo da Chefia de Polícia, Relatório da Secretaria de Polícia de 1911, p. 10)

Uma outra linha de explicação para buscar compreender a desproporção entre os problemas carcerários e a capacidade de resolução daqueles pela chefatura de polícia estaria na expansão do encarceramento nas cidades mineiras, fenômeno este detectado pelo chefe de polícia que assinou o relatório de 1901 e visto como uma resposta necessária ao aumento da violência, que por sua vez era entendida como produto da falta de oportunidades em Minas Gerais, fazendo com que

(...) os bons elementos emigrassem á procura de remuneração para a sua atividade licita; outros luctam com sérias dfficuldades sem abandonarem, todavia, o trabalho; os maus, porém, permanecendo como meros consumidores, constituírem-se em grave ameaça á ordem ublica e á segurança individual. A moeda falsa, o roubo á mão armada, os artifícios fraudulentos de toda a sorte, são crimes de época, que brotam nas consciencias incultas como solução ás dificuldades do momento. (Arquivo Público Mineiro, Fundo da Chefia de Polícia, Relatório da Chefia de Polícia de 1901, p. 3) 
Frente ao cenário exposto, o chefe de polícia ordenava que fossem detidas "as pessoas encontradas praticando algum crime ou em fuga perseguidas pelo clamor publico; as pronunciadas e evadidas das prisões; os ébrios; os danificadores de arvores e edifícios públicos ou particulares, quando surpreendidos na pratica de taes actos, e os vagabundos reconhecidos." (Arquivo Público Mineiro, Relatório da Chefia de Polícia de 1901, p. 4-5). Eram encarcerados, portanto, indivíduos que aos olhos de hoje cometiam faltas relevantes ("as pessoas encontradas praticando algum crime ou em fuga perseguidas pelo clamor publico; as pronunciadas e evadidas das prisões”), mas também aqueles que estavam em situações que mesmo sendo moralmente reprováveis configuravam faltas de baixo potencial ofensivo ("os ébrios; os danificadores de arvores e edifícios públicos ou particulares, quando surpreendidos na pratica de taes actos, e os vagabundos reconhecidos"). Essa fala ajuda a explicar, por sua vez, um outro lado do aumento dos presos das cadeias locais, que não necessariamente tinha a ver com o crescimento de crimes, mas, de outro lado, possuía provável conexão com a expansão de desocupados exposta pelo chefe de polícia no parágrafo anterior. (Arquivo Público Mineiro, Relatório da Chefia de Polícia de 1901, p. 4-5).

\section{FONTES}

Arquivo Público Mineiro, Relatórios da Secretaria de Polícia, filmes 001003, negativo F-5 (1895-1918).

Arquivo Público Mineiro, Fundo da Chefia de Polícia, POL 12, Cx 01, Pc 03, 1890.

Arquivo Público Mineiro, Fundo da Chefia de Polícia, POL 12, Cx 02, Pc 05, set. 1891.

Arquivo Público Mineiro, Fundo da Chefia de Polícia, POL 12, Série 12, Cx 3, Pc 4, nov/1892.

Arquivo Público Mineiro, Fundo da Chefia de Polícia, POL 12, Cx 04, Pc 8, jul/1893. 
Arquivo Público Mineiro, Fundo da Chefia de Polícia, POL 12, Cx 05, Pc 09, dez./1894.

Arquivo Público Mineiro, Fundo da Chefia de Polícia, POL 12, Cx 20, Pc 01,12, 07, 1902.

Arquivo Público Mineiro, Fundo da Chefia de Polícia, POL 12, Cx 21, Pc 05-06, set/1903-dez. 1904.

Arquivo Público Mineiro, Fundo da Chefia de Polícia, Relatório da Secretaria de Polícia, 1901, p. 3-17.

Arquivo Público Mineiro, Fundo da Chefia de Polícia, Relatório da Secretaria de Polícia de 1902, p. 21

Arquivo Público Mineiro, Fundo da Chefia de Polícia, POL 12, Cx 22, Pc 09, janeiro/1904.

Arquivo Público Mineiro, Fundo da Chefia de Polícia, Relatório da Secretaria de 1905, p. 5-6.

Arquivo Público Mineiro, Fundo da Chefia de Polícia, POL 12, Cx 29, Pc 05, 1909.

Arquivo Público Mineiro, Fundo da Chefia de Polícia, POL 12, Cx 30, Pc 02, maio, set. e ago./1910.

Arquivo Público Mineiro, Fundo da Chefia de Polícia, POL 12, Cx 30, Pc 08, jul e dez./1911.

Arquivo Público Mineiro, Fundo da Chefia de Polícia, POL 12, Cx 31, Pc 03, jul/1911.

Arquivo Público Mineiro, Fundo da Chefia de Polícia, Relatório da Secretaria de Polícia de 1911, p. 10-38.

Arquivo Público Mineiro, Fundo da Chefia de Polícia, POL 12, Cx 32, Pc 03, 1913.

Arquivo Público Mineiro, Fundo da Chefia de Polícia, Relatório da Secretaria de Polícia de 1913, p. 15.

Arquivo Público Mineiro, Fundo da Chefia de Polícia, POL 12, Cx 33, Pc 01, set./1914.

Arquivo Público Mineiro, Fundo da Chefia de Polícia, Relatório da Secretaria de Polícia de 1914, p. XVIII-49.

Arquivo Público Mineiro, Fundo da Chefia de Polícia, Relatório da Secretaria de Polícia de 1915, p. 21-189. 


\section{REFERÊNCIAS}

AGUIRRE, Carlos. Cárcere e sociedade na América Latina, 1800 - 1940. In: MAIA, Clarissa Nunes (org.). História das prisões no Brasil. Rio de Janeiro: Rocco, 2009.

CANCELLI, Elizabeth. Repressão e controle prisional no Brasil: prisões comparadas. História: Questões \& Debates, Curitiba, n. 42, p. 141156, 2005. Editora UFPR. Disponível em http\%3A\%2F\%2Fojs.c3sl.ufpr. br\%2Fojs2\%2Findex.php\%2Fhi storia\%2Farticle\%2Fdownload\%2F4648\%2F3804\&ei=Def2UfSiCZKO9ATr0o DIBQ\& usg=AFQjCNHHMITxDiK46oanmde0GpJgbAdtzg. Acesso em: 16 jul. 2013.

FAUSTO, Boris. Controle social e criminalidade em São Paulo: um apanhado geral (1890-1924). In: PINHEIRO, Paulo Sergio (org.). Crime, violência e poder. São Paulo: Brasiliense, 1983, p. 193-224.

FAUSTO, Boris. Crime e cotidiano: a criminalidade em São Paulo: (18801924). 2. ed. São Paulo: EDUSP, 2001.

GEERTZ, Clifford. A interpretação das culturas. Rio de Janeiro: LTC, 2008.

GALVAO, Walnice Nogueira. Prezado senhor, prezada senhora: estudos sobre cartas. São Paulo: Companhia das Letras.

GOMES, Angela Maria de Castro. Escrita de si, escrita da história. Rio de Janeiro: Ed. FGV, 2004.

GRINBERG, Keila. A história nos porões dos arquivos judiciários. In: Carla Pinski e Tânia de Luca. In: PINSKY, Carla Bassanezi.; DE LUCA, Tania Regina. O historiador e suas fontes. São Paulo: Editora Contexto, 2009. HOLLOWAY, Thomas. O calabouço e o aljube do Rio de Janeiro no século XIX. In: MAIA, Clarissa Nunes et al. História das prisões no Brasil. Rio de Janeiro: Editora Rocco, 2009.

MAIA, Clarissa Nunes (org.). História das prisões no Brasil. Rio de Janeiro: Rocco, 2009.

MAIA, Clarisse Nunes. História e historiografia das prisões. In: MAIA, Clarissa Nunes (org.). História das prisões no Brasil. Rio de Janeiro: Rocco, 2009. 
MALATIAN, Teresa. Narrador, registro e arquivo. In: PINSKY, Carla Bassanezi.; DE LUCA, Tania Regina. O historiador e suas fontes. São Paulo: Editora Contexto, 2009.

PERROT, Michelle (org). L' impossible prision - Recherches sur le système pénitentiaire au XIX siècle. Seuil, 1980.

PERROT, Michelle. O inspetor Bentham - Le Panoptique, Paris: P. Belfond, 1977. In: BENTHAM, Jeremy et. al [organização de Tomaz Tadeu]. O Panóptico. 2. ed. Belo Horizonte: Autêntica Editora, 2008.

PERROT, Michelle. Os excluídos da história: operários, mulheres e prisioneiros [seleção de textos e introdução de Stella Bresciani]; tradução, Denise Bottmann. Rio de Janeiro: Paz e Terra, 2001.

ROSEMBERG, André; SOUZA, Luís Antônio Francisco de. Notas sobre o uso de documentos judiciais como fonte de pesquisa histórica. Patrimônio e Memória, v. 5, n. 2, p. 159-173, dezembro/2009. Disponível em http:// hdl.handle.net/11449/108033. Acesso em: 29 ago. 2016.

SANTANA, Aline Passos de Jesus. A disciplina carcerária na sociedade de controle: uma análise genealógica do Regime Disciplinar Diferenciado. 2011. Dissertação (Mestrado em Ciências Sociais) - Pontifícia Universidade Católica de São Paulo. São Paulo, p. 12-86. Disponível em http://www.sapientia.pucsp.br/tde_arquivos/8/TDE-2012-01-30T06:35:47Z12039/Publico/ Aline\%20Passos\%20de\%20Jesus\%20Santana.pdf. Acesso em: 21 jul 2013.

VELLASCO, Ivan de Andrade As seduções da ordem: violência, criminalidade e administração da justiça, Minas Gerais, século 19. Bauru: EDUSC, Anpocs, 2004.

\section{CAMILA SIMILHANA OLIVEIRA DE SOUZA}

Doutora em História pela UFMG, mestre em Ciências Sociais pela PUC-Minas, bacharela e licenciada em História pela PUC-Minas.

Endereço profissional: Av. Pres. Antônio Carlos, 6627 - Pampulha, Belo Horizonte - MG, 31270-901, Brasil.

ORCID ID: https://orcid.org/0000-0002-6774-6742

E-MAIL: similhana@yahoo.com.br 
Recebido: 07/05/2020

Aceito: 18/01/2022

\section{(c) (1)}

Este trabalho está licenciado sob uma licença Creative Commons Attribution 4.0 International License.

Autores e autoras cedem à Revista Sequência direitos exclusivos de primeira publicação, ficando o trabalho licenciado sob a Creative Commons Attribution 4.0 International License. A licença autoriza que terceiros remixem, adaptem e ou criem a partir do trabalho publicado, indicando o crédito ao trabalho original e sua publicação inicial. Os autores têm permissão para assumir contratos adicionais em separado, com distribuição não exclusiva da versão publicada na Revista Sequência, indicando, de todo modo, a autoria e publicação inicial neste periódico. 